\title{
Canalith Repositioning Variations for Benign Paroxysmal Positional Vertigo
}

\author{
Helen S. Cohen, EdD, OTR ${ }^{1}$ and Haleh Sangi-Haghpeykar, PhD $^{2}$ \\ ${ }^{1}$ Bobby R. Alford Department of Otolaryngology - Head and Neck Surgery, Baylor College of \\ Medicine, One Baylor Plaza, Houston, TX 77030 \\ 2Department of Obstetrics and Gynecology, Baylor College of Medicine, One Baylor Plaza, \\ Houston, TX 77030
}

\begin{abstract}
Objective-To determine if variations in common treatments for benign paroxysmal positional vertigo (BPPV) affected efficacy.
\end{abstract}

Study Design-Prospective, pseudo-randomized study.

Setting-Out-patient practice in a tertiary care facility

Subjects and Methods-Patients $(n=118)$ with unilateral BPPV of the posterior canal, including 13 patients with BPPV of the lateral canal were tested at a tertiary care center on one of five interventions: canalith repositioning maneuver (CRP), CRP plus home exercise, modified CRP, CRP for patients with involvement of two semicircular canals, self-CRP home exercise. Self-CRP was also compared to previously published data on efficacy of the Brandt Daroff exercise. Main outcome measures were vertigo intensity and frequency, presence/ absence of DixHallpike responses, Vestibular Disorders Activities of Daily Living Scale (VADL), computerized dynamic posturography.

Results-Vertigo intensity and frequency and Dix-Hallpike responses decreased significantly and posturography and VADL improved significantly from pre- to post tests. No other significant changes were found. The groups did not differ significantly. Vertigo intensity and frequency were not strongly related at pre-test but were related at post-test. Length of illness and age did not influence the results.

Conclusions-However the head is moved, as long as it is moved rapidly enough and through the correct planes in space repositioning treatments are likely to be effective. Therefore clinicians have a range of choices in selecting the treatment best suited for each patient's unique needs.

\section{Keywords}

vertigo; dizziness; vestibular rehabilitation; repositioning maneuvers; benign positional nystagmus; vestibular

Corresponding author: Helen S Cohen, EdD, OTR, Department of Otolaryngology, Baylor College of Medicine, One, Baylor Plaza, Houston, TX 77030, USA. Telephone: 713-798-6336, FAX: 713-798-8658, hcohen@ bcm.tmc.edu.

Financial Disclosure

Conflict of interest: none 


\section{Introduction}

Benign paroxysmal positional vertigo (BPPV) is a common problem. 1 Since exercises and passive maneuvers to reposition the putatively displaced otoconial matter were first described 2, 3, 4 several treatments have been described, mostly variations on Epley's maneuver (CRP). ${ }^{5}, 6,7,8,9$ A self-CRP exercise has been described ${ }^{10}$ but only one study has reported its effectiveness. ${ }^{11}$ In that study subjects had either a single out-patient CRP or home self-CRP three times daily for one week. Results were better in the home exercise group but the greater amount of treatment may have been the cause. No studies have yet compared the effectiveness of self-CRP to the older, Brandt Daroff exercise.

Recently, Rajguru et al, at University of Utah, modeled the ideal CRP based on the predicted mechanics of otoconial matter within the vestibular labyrinth. ${ }^{12}$ They suggested that CRP would be more effective if the head was moved in a slightly different pattern than the classic CRP. ${ }^{13}$ Faldon and Bronstein's work suggests that as long as the head is moved with sufficient acceleration a maneuver should be successful. ${ }^{14}$

We compared CRP without medication, mastoid vibration or post-treatment head restrictions 15 to groups treated with variations of repositioning treatments. The goal was to determine if any variation was more efficacious than our standard CRP.

\section{Materials Methods}

\section{Subjects}

The 118 subjects ( 28 males, 90 females; aged 26.2 to 83.0 yrs; mean age 56.9, SD 13.0) had unilateral BPPV for at least one week (median $8.7 \mathrm{wks}$, range 1 week to 15 years) and were referred to the senior author for vestibular rehabilitation. No subjects had been treated for BPPV previously. Most subjects had involvement of only the posterior semicircular canal. Some subjects also had lateral semicircular canal BPPV. (Table 1.)

Referring physicians, board-certified otolaryngologists and neurologists, at this institution and in the community, made all diagnoses based on their clinical examinations and objective diagnostic testing. Every subject had a unilaterally positive Dix-Hallpike test with nystagmus beating upward and ipsilaterally.16 Subjects with lateral canals involved also had unilateral, positive responses to positional tests lying on the involved side. ${ }^{16}$ During DixHallpike and positional tests, eye movements were recorded with infrared videooculography and analyzed using software from Micromedical Technologies (Spectrum Software version S3.0.1). At the discretion of their physicians some subjects also had a full battery of bi-thermal caloric tests, low-frequency harmonic acceleration tests, and vestibular-evoked myogenic potentials. Every subject was tested by one of three experienced technicians who, collectively, had 51 to 55 years of experience, and were blinded to subjects' group assignments.

All subjects had cervical range of motion within functional limits; age-appropriate strength and motor coordination; no significant orthopedic, neurologic, or other otologic disorders; weight within range for computerized dynamic posturography, i.e. less than $136 \mathrm{~kg}$, and were competent to give informed consent. All patients who met the inclusion criteria were invited to participate. (Figure 1.)

\section{Treatment Groups}

Group 1 received 3 trials of a standard CRP described previously: ${ }^{15}$ 1) Dix-Hallpike maneuver, 2) head turned $90^{\circ}$ contralaterally (Figure $2 \mathrm{~A}$ ), 3) torso and head turned $30^{\circ}$ further contralaterally (Figure 2B.3), 4) sit up, head turned contralaterally (not shown). The 
head was maintained in each position for 10 seconds after vertigo ceased or for at least 30 seconds if no vertigo was elicited. This inter-position interval was used in all groups. No premedication, mastoid vibration or home instructions for head position were used.

In Group 2, which had involvement of 2 semicircular canals, subjects also received 3 trials of CRP as in Group 1. Group 2 was smaller because fewer patients present with two-canal involvement. The inter-trial interval was 2 to 3 minutes.

Group 3 received 3 trials of CRP and practiced a home program using the Brandt Daroff exercise ${ }^{17}$ modified to keep the head turned so that the nose pointed approximately $30^{\circ}$ away from the involved side throughout the exercise (approximately, because controlling the exact head position used at home was impossible), beginning by sitting on the side of her bed: 1) the subject briskly laid down on the ipsilateral side, 2) the subject briskly laid on the contralateral side, 3 ) the subject sat up. They performed 5 trials per session, 3 times daily: before breakfast, mid-day or upon returning home from work, and at bedtime.

Group 4 received 3 trials of CRP modified from the CRP used for Group 1, based on the computational model of CRP (Utah CRP). ${ }^{12}$ Steps 1 to 3 were the same. Step 4) sit-up approximately $45^{\circ}$ with head rotated $-15^{\circ}$ toward the ipsilateral side in yaw rotations, 5) sit up with nose turned to midline, 6) pitch the head downward $30^{\circ}, 7$ ) sit with head erect. (Figure $2 \mathrm{~A}$ and B.) Group 5 practiced a self-CRP exercise at home, ${ }^{10} 3$ trials per session, 3 times daily: before breakfast, mid-day or upon returning home from work, and at bedtime.

\section{Pre- and Post-treatment Tests}

Subjects were pre-tested when they were recruited to the study $\left(\mathrm{T}_{1}\right)$. They were post-tested 1 week after treatment $\left(\mathrm{T}_{2}\right)$ and were tasked to return 3 months $\left(\mathrm{T}_{3}\right)$ and 6 months $\left(\mathrm{T}_{4}\right)$ later. Actual $\mathrm{T}_{3}$ and $\mathrm{T}_{4}$ dates varied based on subjects' personal schedules. All subjects returned at $\mathrm{T}_{2}$. The sample size decreased at later follow-up periods, however, perhaps because some subjects felt no need to return if they felt better. (Table 2). Thus results at $T_{3}$ and $T_{4}$ may be less robust than at $T_{2}$. All available data for every subject were used in the statistical analyses.

Pre- and post-test visits used the same measures. Each subject was asked to rate vertigo intensity and frequency using 10-point scales, where 1 was none and 10 was extreme vertigo (intensity) and where 1 was none and 10 was constant vertigo (frequency). For each scale, the subject viewed a $13 \times 18 \mathrm{~cm}$ card showing each scale and selected the number that most closely matched her experience. Balance was evaluated using computerized dynamic posturography (EquiTest, Neurocom). Subjects also competed the Vestibular Disorders Activities of Daily Living Scale (VADL). ${ }^{18,} 19$

\section{Medication Use}

All subjects were instructed to avoid taking Antivert, generic meclizine, or other vestibularsuppressant medications for at least 24 hours before their first visit and to avoid taking them for the duration of participation in the study. No subjects received medication, special instructions about sleeping position, or mastoid vibration during treatment.

\section{Informed consent, pseudorandomization, blinding}

This study was approved by the Institutional Review Board for Human Subject Research for our institution. Subjects gave informed consent before administration of pretreatment study assessments. The sample size was calculated for power $=0.8$, based on previous data. ${ }^{15}$ With alpha set to 0.05 , a sample size of 26 per group was adequately powered (80\%) to detect a difference in average change of 1.4 units in vertigo intensity or frequency (on a 10- 
point vertigo scale) between any two groups when standard deviation (SD) at baseline was 1.6 or less. For group $2(\mathrm{~N}=13)$ comparisons, difference in average change detectable was about 1.7 units, using SD at baseline of 1.6 or lower.

Subjects completed study questionnaires, were tested on computerized dynamic posturography, and were assigned to groups. Except for subjects with involvement of two semicircular canals, who were assigned to Group 2, the senior investigator assigned groups from a spreadsheet in which the groups had been pseudo-randomized a priori, to maintain the sample size per group. If a subject in a group dropped out, i.e. did not return for the posttest at $\mathrm{T}_{2}$ despite reminders, the next subject who was recruited to the study was placed in that group, to maintain the group size. Tests on $\mathrm{T}_{1}$ were performed before group assignments were made.

\section{Statistical Methods}

Multilevel statistical methods ${ }^{20}$ were used to describe changes in primary outcomes of interest between the five study groups. A separate model was produced and fitted to each outcome. Within each model, we examined significance of within subject effect over time as well as differences among the 5 study groups. Interaction effects were included in each model and tested. Changes over time were compared between study groups by using a likelihood ratio statistic, which follows a chi-square distribution. Adjustments were made for multiple comparisons. $\mathrm{P}<.05$ was considered statistically significant. All analyses were performed using SAS Statistical software (SAS, Carry, NC).

\section{Results \\ Vertigo measures}

For all groups vertigo intensity and frequency decreased significantly from pre-test to the one-week post-test and plateaued after that. Vertigo frequency (mean (SD/range) at pre-test was $5.3(1.8 / 2-10)$, at $\mathrm{T}_{2}$ was $2.4(1.4 / 1-7)$, at $\mathrm{T}_{3}$ was $2.2(1.7 / 1-9)$ and at $\mathrm{T}_{4}$ was $2.1(1.7 /$ $1-8)$. Vertigo intensity mean (SD/range) at pre-test was $5.7(1.7 / 2-10)$, at $\mathrm{T} 2$ was $2.6(1.7 / 1-$ $9)$, at $\mathrm{T} 3$ was $2.4(1.9 / 1-9)$ and at $\mathrm{T}_{4}$ was 2.3 (2.0/ 1-9). The groups did not differ significantly. (Figure 3.)

The relationship between vertigo intensity and frequency over time was tested with Spearman rank order correlations with the groups collapsed. At $\mathrm{T}_{1}$ the relationship was weak: $r=0.3, p=0.0002$. At $T_{2}$ the relationship was stronger: $r=0.8, p<0.0001$. At $T_{3}$ the relationship was even stronger: $\mathrm{r}=0.95, \mathrm{p}<0.0001$. At $\mathrm{T}_{4}$ the relationship remained very strong: $r=0.95, p<0001$. (Figure 4.)

\section{Posturography scores}

Equilibrium scores on Condition 5 (eyes closed, sway-referenced force platform motion) increased from $T_{1}$ to $T_{2}$, with no further changes at later tests. Group 5 had significantly lower (worse) equilibrium scores at than Group 1, CRP, at $\mathrm{T}_{2}$. No other differences were found among groups. (Table 1.) The number of falls decreased from preto post-test, with no further changes at later tests. Group 5, self-CRP, had more falls than other groups at pre-test but other groups did not differ significantly. (Table 1.)

\section{VADL scores}

The VADL scale was normed using the median score. We tested the scores using the means and the medians. Overall similar results were obtained with means and medians. On the mean total score, the groups did not differ significantly. With the groups collapsed total scores decreased (improved) significantly from $T_{1}$ to $T_{2}(F=13.3, p<0.0001)$, but did not 
change significantly after $T_{2}$. Functional, ambulation and instrumental subscores all decreased significantly from $T_{1}$ to $T_{2}$ (Functional: $F=23.96, p<0.0001$; Ambulation: $F=$ 8.7, $\mathrm{p}<0.0001$; Instrumental: $\mathrm{F}=10.9, \mathrm{p}<0.0001$ ) and then did not change significantly at $\mathrm{T}_{3}$ and $\mathrm{T}_{4}$. (Table 2.)

\section{Dix-Hallpike responses}

We tested presence or absence of nystagmus with a classical response pattern, i.e. horizontal and torsional quick phases beating ipsilaterally, upward-beating vertical quick phases. All subjects had nystagmus at $T_{1}$. The groups did not differ significantly at $T_{2}, T_{3}$ or $T_{4}$. The presence of nystagmus decreased significantly from $\mathrm{T}_{1}$ (when all subjects had nystagmus) to $\mathrm{T}_{2}(39.8 \%)(\mathrm{p}<0.0001)$, and remained significant at $\mathrm{T}_{3}(37.3 \%)$ and $\mathrm{T}_{4}(39.6 \%)(\mathrm{p}<0.0001)$. After $\mathrm{T}_{2}$ nystagmus did not decline significantly.

\section{Length of illness}

We tested the relationship between the length of time subjects had vertigo when they enrolled in the study, i.e. length of illness (LOI) and vertigo intensity, vertigo frequency, age, and presence or absence of response to the Dix-Hallpike maneuver at $T_{1}$. Without the subject who reported having had vertigo for 15 years, which may have been inaccurate, regression showed that neither vertigo intensity, vertigo frequency, nor age were related to LOI: intensity/LOI, $\mathrm{F}=2.37, \mathrm{p}=0.13$; frequency/LOI, $\mathrm{F}=2.43$, $\mathrm{p}=0.12$; age/LOI, $\mathrm{F}=0.12$, $\mathrm{p}=0.73$. The relationship between Dix-Hallpike response and LOI was analyzed with an odds ratio; that test was also nonsignificant: odds ratio $=1.0, \mathrm{p}=0.96$. This finding confirms previous results. ${ }^{15}$

\section{Self-CRP group compared to previous Brandt Daroff group}

Previous work suggested that the modified Brandt Daroff exercise was significantly more effective than a sham treatment and slightly less effective than CRP. ${ }^{15}$ Those data were collected under comparable conditions, using the same staff. Therefore, we compared the present self-CRP group (Group 5) to the previous data on the Brandt Daroff exercise. Unlike the present Group 3 the previous Brandt Daroff group subjects did not also receive CRP. Thus, this comparison pairs two groups of similar subjects that only practiced a home exercise.

The self-CRP and Brandt Daroff groups did not differ significantly on vertigo intensity or frequency at any test dates. At $\mathrm{T}_{1}$ the self-CRP group had significantly lower VADL Total scores than the Brandt Daroff group ( $\mathrm{t}=2.0, \mathrm{p}=0.04)$, and significantly lower Ambulation subscores $(\mathrm{t}=2.10, \mathrm{p}=0.03)$. The two groups did not differ significantly on Functional and Instrumental subscores. On VADL Total and Ambulation scores the self-CRP group continued to have lower scores than the Brandt Daroff group but the percent change from $T_{1}$ to $\mathrm{T}_{4}$ did not differ significantly between the two groups. Likewise, VADL Functional and Instrumental subscores declined over tests for both groups with similar percent changes. (Table 3.)

At $T_{2}$ both groups had significantly decreased Dix-Hallpike responses. At $T_{3}$ and $T_{4}$ the self-CRP group did not differ significantly different from $\mathrm{T}_{2}$. The Brandt Daroff group, however, decreased further at $T_{3}$ and $T_{4}$ so that the change at $T_{4}$ differed significantly from $T_{2}$. The change at $T_{3}$ was intermediate and did not differ from either $T_{2}$ or $T_{4}$. The Brandt Daroff group trended toward differing from the self-CRP group at $\mathrm{T}_{4}$ but the sample sizes were small at those times so differences are probably not meaningful. Larger and longerterm trials are needed to examine this issue. 
On posturography, SOT Condition 5, both groups had decreased scores and some falls at pre-test, but improved significantly over time. The groups did not differ significantly. (Table 1.)

\section{Discussion}

The lack of differences among groups indicates that some variations in treatment methodology do not reduce the effectiveness of care. CRP has been shown to be significantly more effective than a sham treatment and slightly more effective than Brandt Daroff exercise. ${ }^{15}$ This study shows that modifying the CRP, performing CRP plus a home program, or having involvement of a second semicircular canal does not change treatment effectiveness. One week of the self-CRP exercise is as effective as the modified Brandt Daroff exercise or three trials of CRP and its variations. Thus, self-CRP is an effective home program. It may be preferred for patients who have limited ability to sit up quickly.

This study replicated previous findings showing that CRP is effective in reducing vertigo and responses to the Dix-Hallpike maneuver. ${ }^{8,15,21,22}$ and improving posturography and VADL scores. ${ }^{15}$ Previous work 23,24 supports the finding that CRP plus a home program does not improve the outcome. By contrast, Tanimoto et al found that CRP, alone, was less effective than CRP plus self-CRP at home, ${ }^{11}$ perhaps due to paradigm differences.

Consistent with previous research ${ }^{15}$ subjects in Groups 1,2,3 and 4 were all treated at $T_{1}$ and did not receive CRP at subsequent dates. Since some patients may need a second or third treatment ${ }^{25}$ the finding that some subjects were still symptomatic at $\mathrm{T}_{2}$ is not surprising. Also, some patients may have had subclinical Dix-Hallpike responses without concomitant vertigo. The underlying pathophysiology in such cases may have been residual otoconial matter in the semicircular canals. Anatomical work has shown that otoconial matter may be present in the semicircular canals of people who had not complained of vertigo in life. ${ }^{26}$ Groups 3 and 5 practiced home exercise for a week. With the availability of the Internet some patients may try to treat themselves with instructions for exercises that they find online. Therefore, an important area for future research might be to determine the optimal treatment for subjects who self-treat with exercise.

The relationship between vertigo frequency and intensity changes over time. Before treatment vertigo frequency and intensity are weakly related. After treatment vertigo frequency and intensity are strongly related, suggesting that they co-vary with improvement after care. This finding provides indirect support for the theory that BPPV is caused by otoconial matter displaced into the semicircular canal. If the particles become relocated to the utricle then the frequency of episodes and the intensity of sensation should decrease as fewer particles remain in the involved canal.

CRP is a robust treatment technique. As performed in this study CRP is as effective as the liberatory maneuver, ${ }^{4} \mathrm{CRP}$ without the second $90^{\circ}$ turn, and CRP with additional "shaking" head motions, ${ }^{15,27}$ with other variations on CRP with medication and compared to a notreatment control group, ${ }^{28}$ compared to a different sham group than that used by Cohen and Kimball ${ }^{21}$ for more than 3 trials, ${ }^{8}$ or with variations in the duration of each position. ${ }^{21}$ Some investigators have used cervical collars, ${ }^{22}$ but CRP is effective without them. Vibration and postural restrictions do not influence effectiveness. ${ }^{29,} 30$ Repositioning treatments appear to be efficacious, regardless of minor differences among maneuvers. If the head is moved in the appropriate motions, and rapidly enough -- approximately $55 \%$ second to $75 \%$ second, ${ }^{14}$ the treatment is likely to be effective. Thus, minor variations in technique may not substantially influence the outcome of treatment and the clinician can be confident in using repositioning treatments with a wide variety of patients. 
The clinician has several options for care and may tailor the treatment plan to meet the needs of the individual patient as long as the basic requirements for head movement are met. Several trials of CRP given in the out-patient clinic may be preferable because CRP takes only a few minutes but a home program takes several days. Therefore, the clinician need not feel obligated to recommend a home program, especially when musculoskeletal limitations make a home exercise program contraindicated.

The home-based repositioning exercises described here are effective, but with a caveat. The patient must be instructed properly. Patients do not learn exercises from printed directions. In this study, the senior author explained the premise of the exercise, demonstrated it herself, had the patient practice it, reiterated the instructions, give the patient written instructions to take home, and than had the patient repeat the instructions and ask questions. This process takes time. During treatment planning the clinician should decide if she has time to instruct the patient in home exercise or if office-based CRP would be as effective and more efficient. The recurrence rate for BPPV is high ${ }^{24}$ so some patients may have recurrences. The clinician could use CRP in the office and then give a home exercise for use initially in the case of a recurrence. The patient could be encouraged to return for out-patient care if the home-based exercise does not resolve the symptoms.

\section{Acknowledgments}

We thank the staff of the Center for Balance Disorders, Baylor College of Medicine, and Ondrej Cakrt, MSc, PT, Second Medical Faculty, Charles University, for their invaluable technical assistance.

Source of support

Supported by NIH grant R01 DC003602.

\section{References}

1. von Brevern M, Radtke A, Lezius F, et al. Epidemiology of benign paroxysmal positional vertigo. A population based study. J Neurol Neurosurg Psychiatry 2007;78:710-715. [PubMed: 17135456]

2. Brandt T, Daroff RB. Physical therapy for benign paroxysmal positional vertigo. Arch Otolaryngol Head Neck Surg 1980;106:484-485.

3. Epley JM. The canalith repositioning procedure: for treatment of benign paroxysmal positional vertigo. Otolaryngol Head Neck Surg 1992;107:399-404. [PubMed: 1408225]

4. Semont A, Freyss G, Vitte E. Curing the BPPV with a liberatory maneuver. Adv Oto Rhino Laryngol 1988;42:290-293.

5. Massoud ES, Ireland DJ. Post-treatment instructions in the nonsurgical management of benign paroxysmal positional vertigo. J Otolaryngol 1996;25:121-125. [PubMed: 8683652]

6. Parnes LS, Price-Jones RG. Particle repositioning maneuver for benign paroxysmal positional vertigo. Ann Otol Rhinol Laryngol 1993;102:325-331. [PubMed: 8489160]

7. Welling DB, Barnes DE. Particle repositioning maneuver for benign paroxysmal positional vertigo. Laryngoscope 1994;104:946-949. [PubMed: 8052079]

8. Yimtae K, Srirompotong S, Srirompotong S, Sae-seaw P. A randomized trial of the canalith repositioning procedure. Laryngoscope 2003;113:828-832. [PubMed: 12792318]

9. Harvey SA, Hain TC, Adamiec LC. Modified liberatory maneuver: effective treatment for benign paroxysmal positional vertigo. Laryngoscope 1994;104:1206-1212. [PubMed: 7934589]

10. Radtke A, Neuhauser H, von Brevern M, Lempert T. A modified Epley's procedure self-treatment of benign paroxysmal positional vertigo. Neurology 1999;53:1358-1360. [PubMed: 10522903]

11. Tanimoto H, Doi K, Katata K, Nibu K-i. Self-treatment for benign paroxysmal positional vertigo of the posterior semicircular canal. Neurology 2005;65:1299-1300. [PubMed: 16247062]

12. Rajguru SM, Ifediba MA, Rabbitt RD. Three-dimensional biomechanical model of benign paroxysmal positional vertigo. Ann Biomed Eng 2004;32:831-846. [PubMed: 15255214] 
13. Brandt T, Steddin S, Daroff RB. Therapy for benign paroxysmal positioning vertigo, revisited. Neurology 1994;44:796-800. [PubMed: 8190277]

14. Faldon ME, Bronstein AM. Head accelerations during particle repositioning manoeuvres. Audiol Neurotol 2008;13:345-356.

15. Cohen HS, Kimball KT. Effectiveness of treatments for benign paroxysmal positional vertigo of the posterior canal. Otol Neurotol 2005;26:1034-1040. [PubMed: 16151355]

16. Coats, AC. Electronystagmography. In: Bradford, LJ., editor. Physiological Measures of the Audio-Vestibular System. New York: Academic Press; 1975. p. 37-85.

17. Radtke A, von Brevern M, Tiel-Wilck K, Mainz-Perchalla A, Neuhauser H, Lempert T. Selftreatment of benign paroxysmal positional vertigo: Semont maneuver vs Epley procedure. Neurology 2004;63:150-152. [PubMed: 15249626]

18. Cohen HS, Kimball KT. Development of the Vestibular Disorders Activities of Daily Living Scale. Arch Otolaryngol Head Neck Surg 2000;126:881-887. [PubMed: 10889001]

19. Cohen HS, Kimball KT, Adams AD. Application of the Vestibular Disorders Activities of Daily Living Scale. Laryngoscope 2000;110:1204-1209. [PubMed: 10892697]

20. Snijders, T.; Bosker, R. Multilevel Analysis: An Introduction to Basic and Advanced Multilevel Modeling. Thousand Oaks, CA: Sage Publications; 1999.

21. Froehling DA, Bowen JM, Mohr DN, et al. The canalith repositioning procedure for the treatment of benign paroxysmal positional vertigo: a randomized controlled trial. Mayo Clin Proc 2000;75:695-700. [PubMed: 10907384]

22. Lynn S, Pool A, Rose D, Brey R, Suman V. Randomized trial of the canalith repositioning procedure. Otolaryngol Head Neck Surg 1995;113:712-270. [PubMed: 7501382]

23. Helminski JO, Janssen I, Hain TC. Daily exercise does not prevent recurrence of benign paroxysmal positional vertigo. Otol Neurotol 2008;29:976-981. [PubMed: 18698271]

24. Helminski JO, Janssen I, Kotaspouikis D, et al. Strategies to prevent recurrence of benign paroxysmal positional vertigo. Otolaryngol Head Neck Surg 2005;131:344-438.

25. Cohen HS, Jerabek J. Efficacy of treatments for posterior canal benign paroxysmal positional vertigo. Laryngoscope 1999;109:584-590. [PubMed: 10201745]

26. Schuknecht HF. Cupulolithiasis. Arch Otolaryngol Head Neck Surg 1969;90:765-778.

27. Cohen HS, Kimball KT. Treatment variations on the Epley maneuver for benign paroxysmal positional vertigo. Am J Otolaryngol 2004;25:33-37. [PubMed: 15011204]

28. Asawavichianginda S, Isipradit P, Snidvongs K, Spiyaphun P. Canalith repositioning for benign paroxysmal positional vertigo: a randomized, controlled trial. Ear Nose Throat J 2000;79:732-737. [PubMed: 11011494]

29. Hain TC, Helminski JO, Reis IL, Uddin MK. Vibration does not improve results of the canalith repositioning procedure. Arch Otolaryngol Head Neck Surg 2000;126:617-622. [PubMed: 10807329]

30. Casqueiro JC, Ayala A, Monedero G. No more postural restrictions in posterior canal benign paroxysmal positional vertigo. Otol Neurotol 2008;29:706-709. [PubMed: 18520622] 


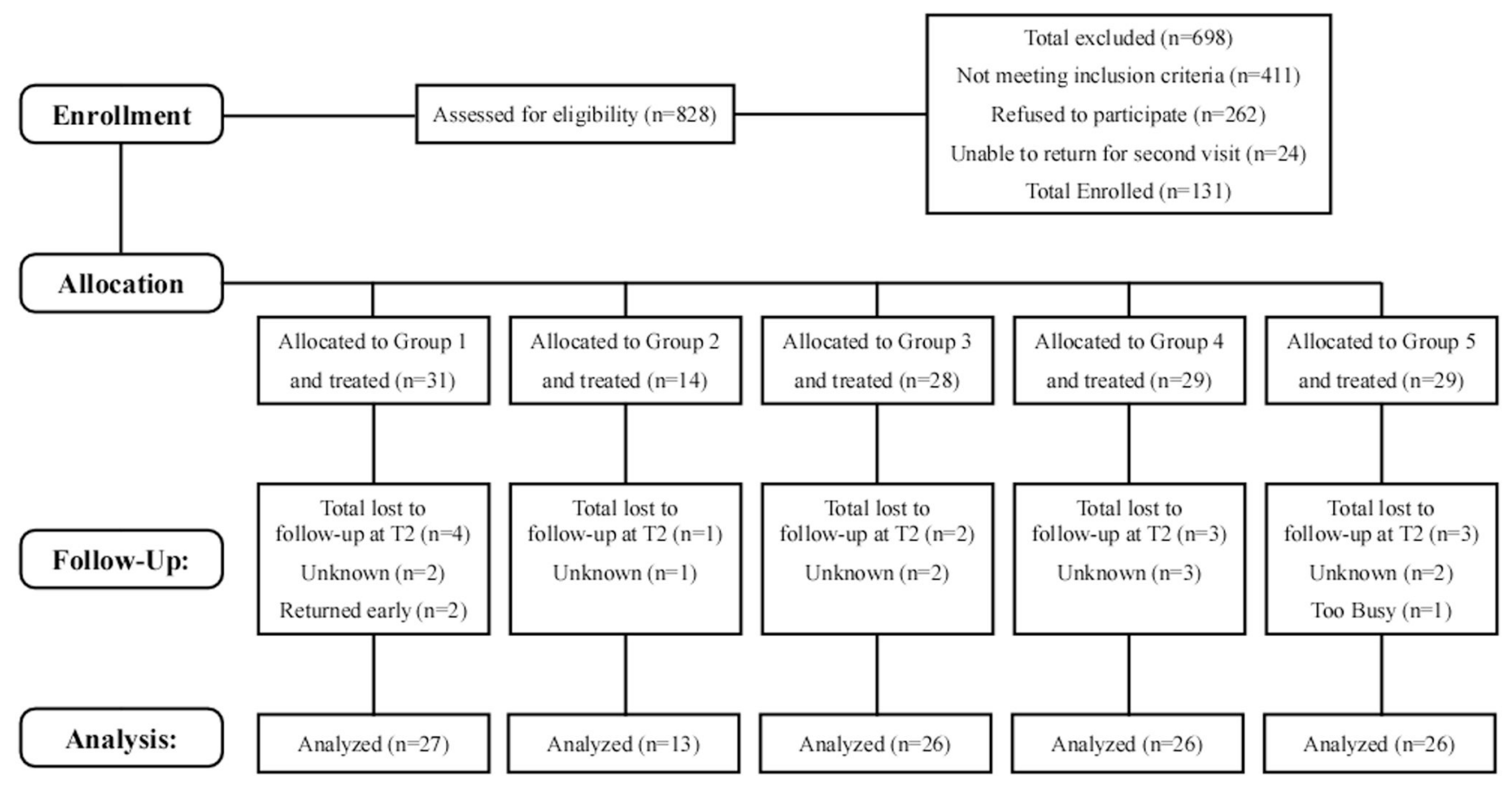

Figure 1.

Consort flow diagram of screening, recruitment and treatment. 

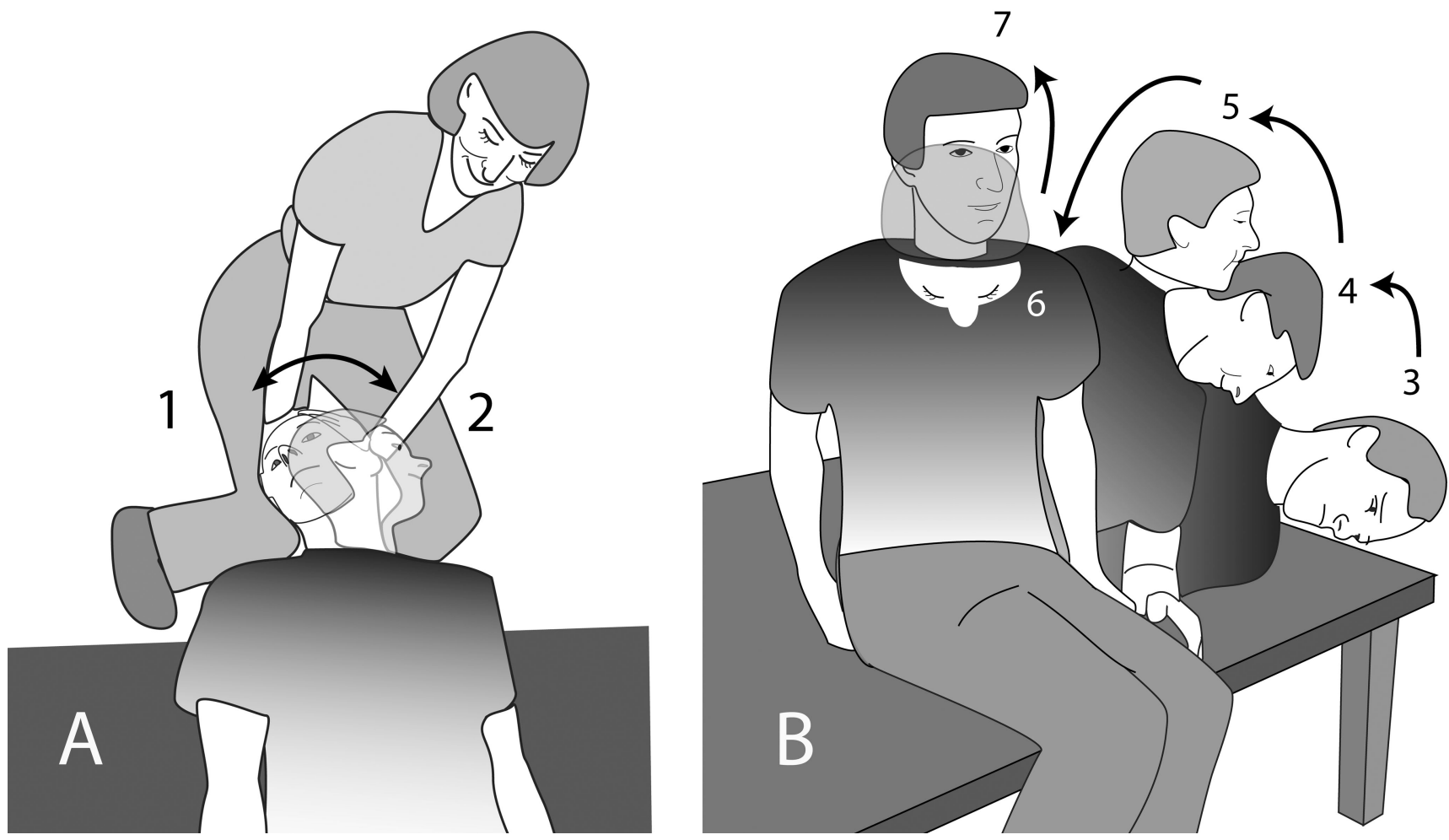

Figure 2.

Diagram of modified CRP used in Group 4. A. Position 1 is the Dix-Hallpike maneuver. In position 2 the head is rotated but the torso remains stationary. Positions 1 and 2 are the same as in CRP. B. In Positions 3 to 7 the head moves and the torso moves from side lying to upright. Position 3 is the same as in CRP. 
A $\quad$ B

CRP

$\triangle$ 2-Canal Involvement $\square$ CRP + Brandt Daroff

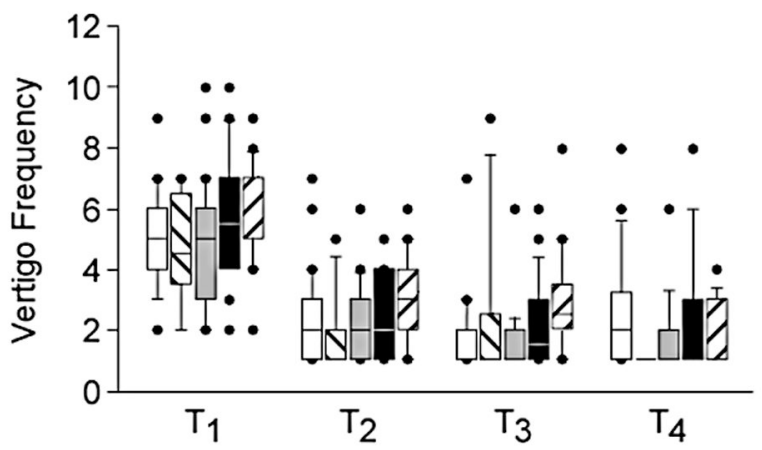

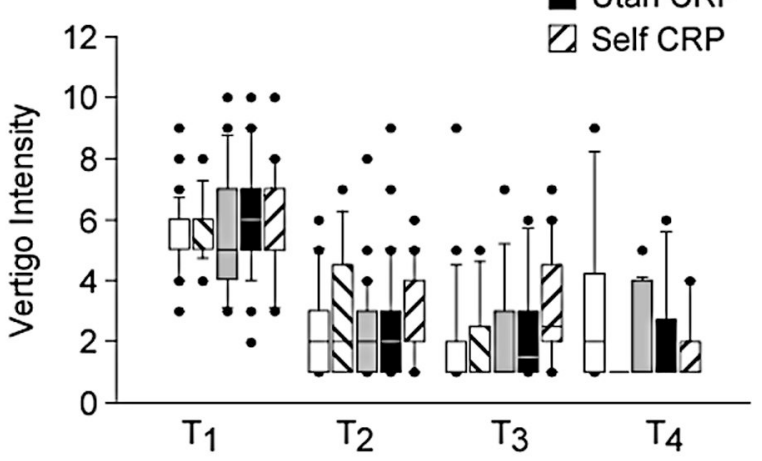

Figure 3.

Changes in vertigo over test time. A. Vertigo frequency. B. Vertigo intensity. Center horizontal bars are medians, rectangle ends are interquartile ranges, error bars are $10^{\text {th }}$ and $90^{\text {th }}$ deciles, circles are outliers. 


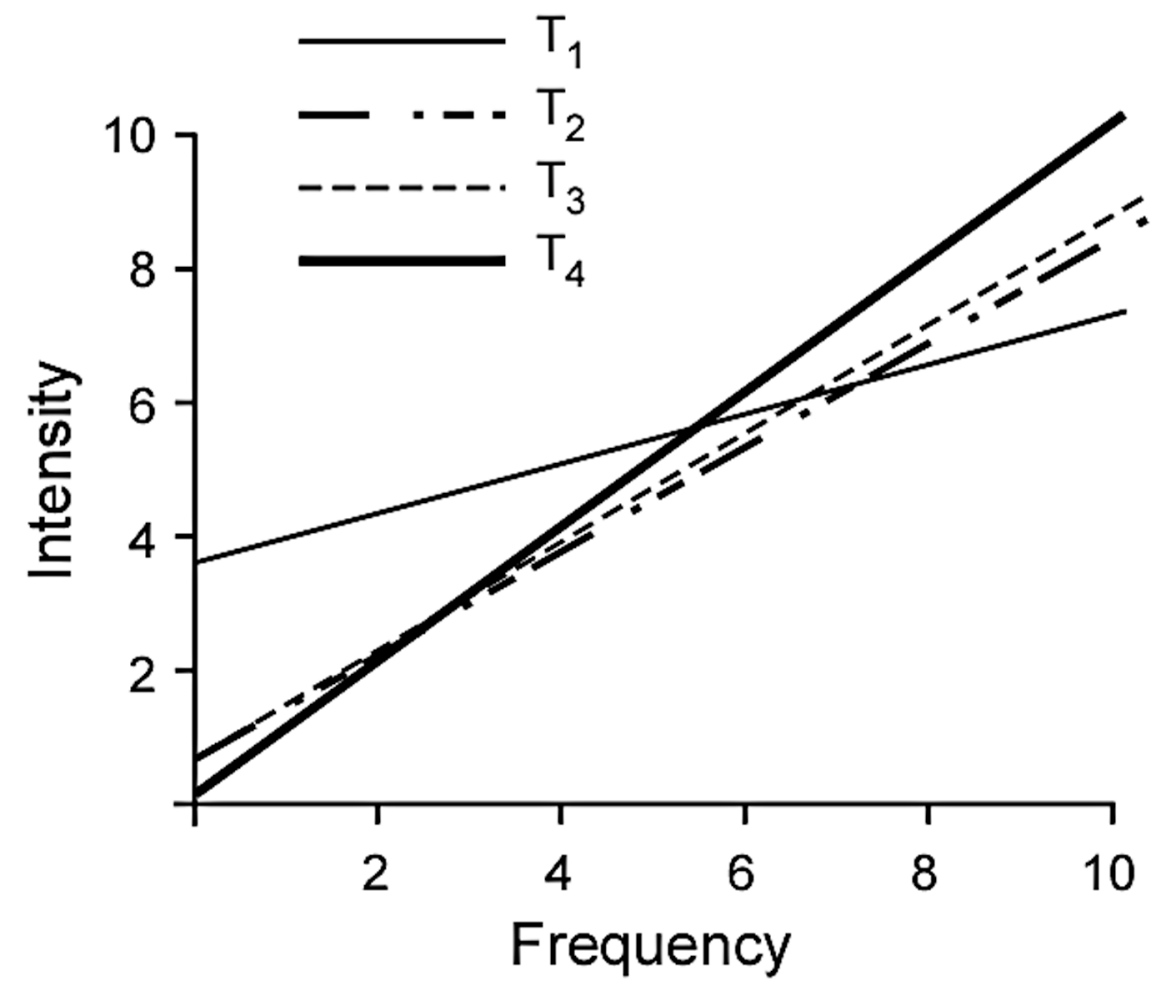

Figure 4.

Correlations between intensity and frequency over test dates. The figure shows the actual regression lines. 


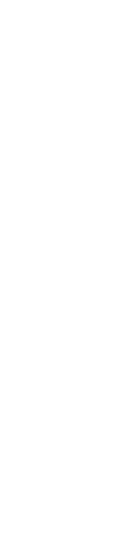

.

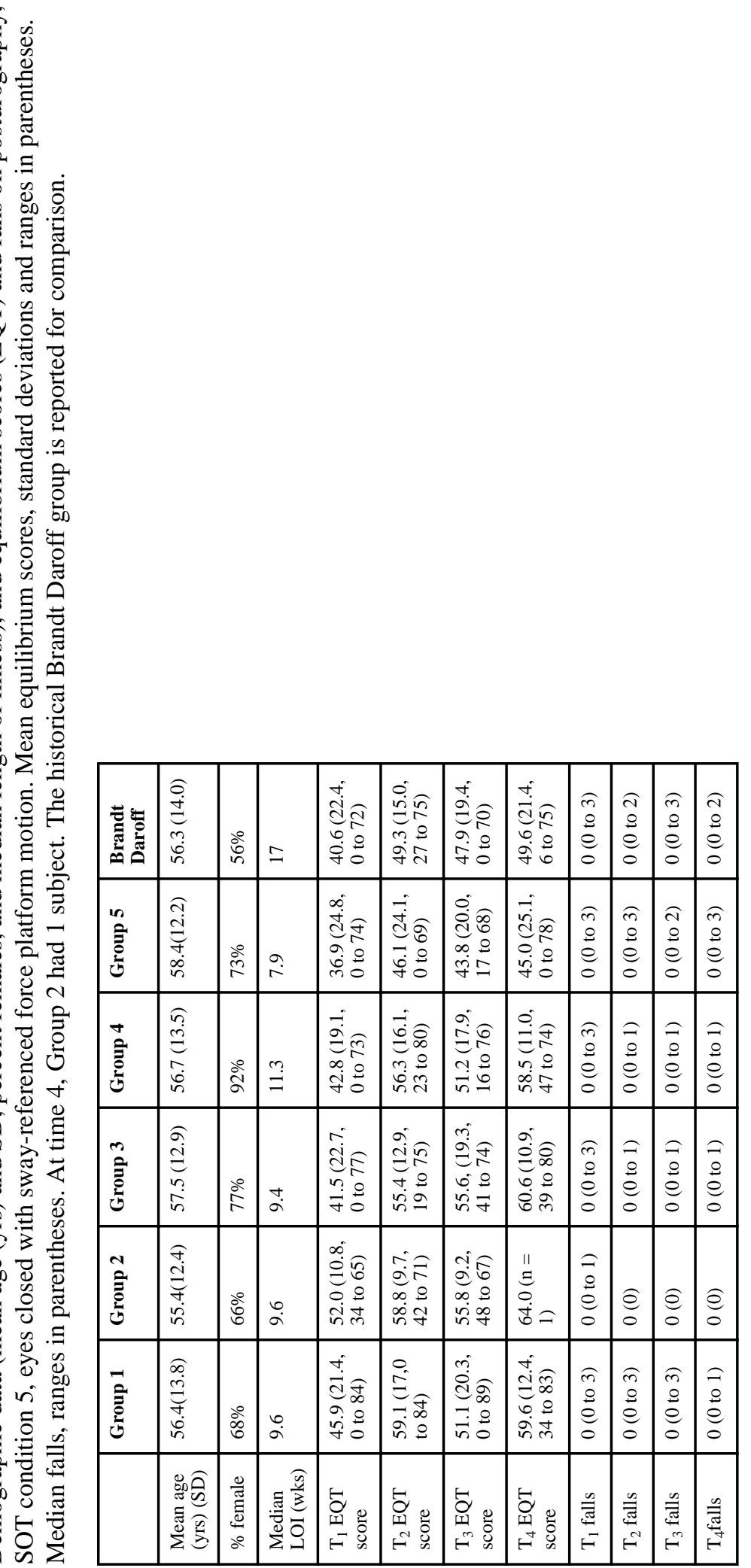

Otolaryngol Head Neck Surg. Author manuscript; available in PMC 2010 December 1. 
Table 2

VADL means with groups collapsed. (Standard deviations, ranges in parentheses).

\begin{tabular}{|l|l|l|l|l|}
\hline & $\mathbf{T}_{\mathbf{1}}$ (n=118) & $\mathbf{T}_{\mathbf{2}}(\mathbf{n}=\mathbf{1 1 8})$ & $\mathbf{T}_{\mathbf{3}}(\mathbf{n}=\mathbf{7 5})$ & $\mathbf{T}_{\mathbf{4}}(\mathbf{n}=\mathbf{5 3})$ \\
\hline Total & $2.4(1.4,1.0-7.3)$ & $\begin{array}{l}1.5(1.0,1.0-7.0) \\
*(\mathrm{p}<0.0001)\end{array}$ & $1.5(0.9,1.0-6.0)$ & $1.6(1.2,1.0-6.0)$ \\
\hline Functional & $2.4(1.3,1.0-5.8)$ & $\begin{array}{l}1.5(0.7,1.0-5.4) \\
*(\mathrm{p}<0.0001)\end{array}$ & $1.4(0.7,1.0-4.0)$ & $1.5(1.0,1.0-5.5)$ \\
\hline Ambulation & $2.3(1.4,1.0-8.8)$ & $\begin{array}{l}1.6(1.0,1.0-7.1) \\
*(\mathrm{p}<0.0001)\end{array}$ & $1.6(1.1,1.0-7.0)$ & $1.5(1.1,1.0-5.4)$ \\
\hline Instrumental & $2.6(2.1,1.0-10.0)$ & $\begin{array}{l}1.6(1.4,1.0-9.0) \\
*(p<0.0001)\end{array}$ & $1.5(1.0,1.0-6.3)$ & $1.7(1.6,1.0-8.1)$ \\
\hline
\end{tabular}

= significant change compared to previous test. 
政

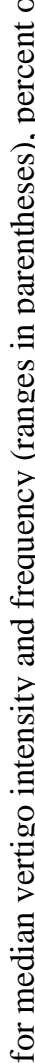

\begin{tabular}{|c|c|c|c|c|c|c|c|c|}
\hline & $F$ & \begin{tabular}{|l}
$\hat{I}$ \\
$\stackrel{I}{\leftrightarrows}$ \\
$n$ \\
$m$
\end{tabular} & $\mid \begin{array}{c}\hat{I} \\
\stackrel{i}{Z} \\
n \\
i\end{array}$ & $\begin{array}{l}\infty \\
\infty \\
\infty \\
\infty\end{array}$ & $\stackrel{\tilde{n}}{=}$ & $\stackrel{\widehat{\hat{I}}}{\stackrel{\underline{V}}{\Xi}}$ & 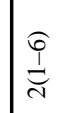 & $\stackrel{\varrho}{\stackrel{\varrho}{I}}$ \\
\hline & $\Leftrightarrow$ & 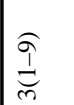 & $\mid \begin{array}{c}\stackrel{\rho}{1} \\
\underset{n}{t}\end{array}$ & $\stackrel{\circ}{\circ}$ & 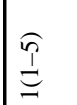 & $\stackrel{6}{9}$ & $\stackrel{I}{I}$ & $\begin{array}{l}\widetilde{n} \\
\stackrel{+}{ \pm} \\
\Xi\end{array}$ \\
\hline 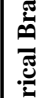 & $\approx$ & 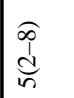 & $\mid \begin{array}{c}\stackrel{0}{1} \\
\stackrel{1}{y}\end{array}$ & $\begin{array}{l}\stackrel{\circ}{\circ} \\
\stackrel{\infty}{\circ}\end{array}$ & 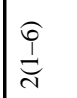 & $\underset{\sim}{\stackrel{n}{n}}$ & 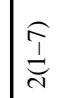 & 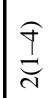 \\
\hline & $=$ & 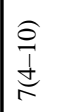 & $\left|\begin{array}{c}\hat{0} \\
d \\
d \\
\end{array}\right|$ & $\stackrel{8}{8}$ & $\frac{\tilde{n}}{\stackrel{n}{n}}$ & 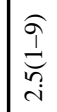 & 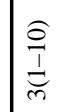 & 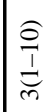 \\
\hline & $\vec{F}$ & $\stackrel{f}{\Xi}$ & $\underset{\underbrace{}}{\stackrel{f}{=}}$ & $\begin{array}{l}\stackrel{0}{ } \\
i n \\
\dot{q}\end{array}$ & $\stackrel{\widehat{\rho}}{\Xi}$ & $\stackrel{\Im}{\Xi}$ & $\underset{\Xi}{\stackrel{f}{\Xi}}$ & $\stackrel{\widehat{I}}{\Xi}$ \\
\hline & $F$ & $\underset{\substack{I \\
\\
i}}{i}$ & $\mid \begin{array}{c}\hat{0} \\
\stackrel{0}{n} \\
\\
i\end{array}$ & $\begin{array}{l}\stackrel{\circ}{\circ} \\
\dot{\gamma}\end{array}$ & $\underset{\Xi}{\stackrel{f}{\Xi}}$ & $\underset{f}{\stackrel{f}{ \pm}}$ & $\underset{\underbrace{}}{\stackrel{f}{\Xi}}$ & $\stackrel{\widehat{P}}{\Xi}$ \\
\hline & $\approx$ & 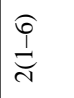 & $\mid \begin{array}{l}0 \\
\stackrel{1}{2} \\
\stackrel{m}{L}\end{array}$ & $\begin{array}{l}\circ \\
\circ \\
\dot{m} \\
\dot{m}\end{array}$ & $\underset{\underbrace{}}{\stackrel{f}{=}}$ & $\underset{\underbrace{}}{\stackrel{f}{=}}$ & $\stackrel{f}{\stackrel{f}{=}}$ & $\stackrel{f}{\Xi}$ \\
\hline & $F$ & 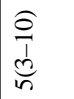 & $\left|\begin{array}{c|}\widehat{d} \\
d \\
\text { d }\end{array}\right|$ & $\stackrel{8}{8}$ & 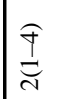 & $\underset{\widetilde{N}}{\stackrel{f}{\tau}}$ & $\underset{\underbrace{}}{\stackrel{f}{\Xi}}$ & 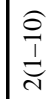 \\
\hline & & 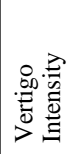 & 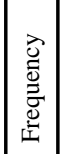 & 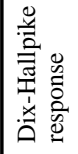 & $\mid \begin{array}{l}\overrightarrow{0} \\
>0 \\
>0\end{array}$ & 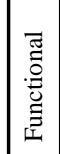 & 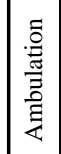 & 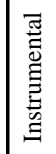 \\
\hline
\end{tabular}

Otolaryngol Head Neck Surg. Author manuscript; available in PMC 2010 December 1. 